\title{
Teacher Leadership: Charismatic Characteristics of \\ Sri Lankan School Teachers \\ ${ }^{1}$ Ukwatta Liyanage Thamara Priyanthi Gunasekare \\ ${ }^{1}$ University of Kelaniya Sri Lanka
}

thamarag@kln.ac.lk

\begin{abstract}
This study identifies a number of charismatic leadership characteristics of school teachers in Sri Lanka. Since charisma is an instrumental asset in any work context, leaders' charismatic characteristics can make extraordinary effects on follower toward mission accomplishment. In the teaching-learning context, teachers are viewed as great leaders that make magnificent transformations in the students. $A$ teacher becomes the leader in the classroom as well and they are playing a significant role to build a culture of learning in the classroom that, finally everyone benefits. Therefore, charismatic leadership characteristics in teachers as leaders can make the teaching-learning process more and more effective. This study followed a qualitative research approach, collecting data from interviewing twenty school teachers. It was reported that most of the school teachers are leaders with charismatic characteristics such as mission formulation for the students, unconditioned commitment towards the students' accomplishments, trust on the students, taking personal risk in directing students, demonstration of unusual behaviors and emotional arousal through attractive communication. The implication of this study is imperative for teacher training and performance appraisals.

Keywords: Teacher leadership, charismatic leadership, teaching-learning process, school teachers
\end{abstract}

JEL $\quad:$ M12, M53

DOI $\quad: 10.24002 /$ kinerja.v22i2.2417

Received : 08/13/2019 Reviewed: 09/25/2019 Final Version: 10/21/2019

\section{INTRODUCTION}

Several large-scale studies have shown that charisma is an invaluable asset in any work context-small or large, public or private, Western or Asian. Further, theories of charismatic leadership focused on the leaders to explain that they put greater expectations on followers through their charismatic characteristics and 
make extraordinary effects. According to the studies of charismatic leadership, such leaders transform the needs, values, preferences, and aspirations of their followers (Javidan \& Waldman, 2003). Further, they affect followers to become highly committed to the mission, to make significant personal sacrifices in the interest of the mission, and to perform above and beyond the call of duty.

Teachers are being viewed as potential human capital in the improvement and transformation of the teaching-learning process. The Teacher Leadership Exploratory Consortium (TLEC) said that teacher are leaders in the learning context. Teachers are often an untapped resource for change and improvement of students. Clearly, genuine systemic change and improvement in students cannot occur without their support. In the review of literature on teacher leadership, YorkBarr and Duke (2004) discovered that teacher leadership arises from teachers' own proficiency and capabilities of instruction and the educational process, which in turn impacts the cultivation of students' knowledge and improvement of their performance. Today what happens in schools is more complex than ever and cannot be accomplished without empowering teachers as the immediate advocates to the students (Muijs \& Harris 2003). They have been proven that they are handling the responsibilities as leaders in making a transformation in the students. If a teacher becomes the leader in the classroom, it helps to change the students' sentiments so that teachers are playing a significant role to build a culture of learning in the classroom and, finally everyone benefits. Due to this nature in schools, the charismatic leadership characteristics in teachers as leaders in the classroom can make the teaching-learning process more and more effective.

Charismatic leadership is also credible in the school context because they convince their subordinates for their own strong motivation, enthusiasm, and commitment. Their actions and decisions are consistent with and support the advocated vision (Javidan \& Waldman, 2003). Waldman, Ramirez, House, \& Puranam (2001) suggested that the behaviors of charismatic leaders included: (1) articulating a vision and sense of mission, (2) showing determination, and (3) communicating high-performance expectations. In addition, the charismatic leader demonstrated that leadership and achievement are a long-term process (Kanter, 1983; Trice \& Beyer, 1993). Richardson and Thayer (1993), similarly, claimed that charismatic leadership is a process rather than a function of personality and hence is highly learnable. They defined charisma as "a specialized set of communication techniques used by leaders to reach the hearts and minds of those that follow them". These techniques include: (i) developing a charismatic persona through optimistic language, passionate commitment, emotional expressiveness, and personal congruence; (ii) creating the bond through physical synchrony, vocal synchrony, matching skills, group alignment, and entertainment; and (iii) managing emotions through impactful words, questions, word pictures, stories, universal experiences, sensory-stimulating language, entraining emotions, conditioned inspiration, physiology management, and leading through values. Elsewhere Smith (2007) said that when charismatic leaders have a mystique, they tend to have a 
high degree of personal presence and command attention through exceptional verbal or nonverbal communication styles. Charismatic leaders are attractive because they seem larger than life in their outlook and create environments that are fun, exciting, or inspirational (Sandberg \& Moreman, 2011). All these accepted wisdom on charismatic leadership describe the distinct nature of charismatic leadership and its capability to create inspiration in followers.

The assumption made in this study is based on the above background. Therefore, I assumed that most of the Sri Lankan school teachers are performing a leadership role by way of inspiring the students for achieving better learning accomplishments via building enthusiasm, commitment, and passion towards the educational mission of the students. Often, this happens due to the leadership of teachers, since teachers as leaders could be able to make a significant impact on the students' mindset and evoke powerful sentiments in the students (Leithwood, Louis, Anderson, \& Wahlstrom, 2004). In their teaching process, while they are interacting with the students, they demonstrate numerous charismatic characteristics that are strongly impactful in changing the student.

Hence, this study makes an effort to uncover what charismatic characteristics are present in the Sri Lankan school teachers. Since it is accepted that charismatic leadership as a most effective leadership style that achieves results through a seductive approach which engages and stimulates followers (Biviano, 2000). This study will be significant in creating awareness about these inspiring characteristics in school teachers, among other related parties to the school education so that they will also be learned and modeled in attainment their educational mission. And this study contributes to building the knowledge base on effective educational leadership and further enrichment of leadership literature along with school climate. An analysis of the qualities of charismatic teachers will shed new light on the teaching process and provide the basis for new teacher training techniques for education.

\section{METHODOLOGY}

The study followed the qualitative approach in which the major research instrument was focus group interviews. In conceptualizing the term "charismatic leadership" a thorough literature survey was carried out. The literature about charismatic traits of the leadership and teacher leadership has been analyzed in order to construct the research frame. The theories of charismatic leadership have been presented by many leadership theorists and according to these theories, there are attribution models and behavioral models of charismatic leadership (House, 1976), (Shamir, House, \& Arthur, 1993), (Conger \& Kanungo, 1987). The review found many common characteristics of charismatic leadership. Some of them are honor, dominance, emotional stability, persistence, enthusiasm, sense of humor, warmth, high tolerance to frustration, objectivity (House \& Aditya, 1997) orientation to a purpose, sensibility to others, empathy (Howell \& Shamir, 2005), 
flexibility and ability to adapt, courage, vitality and emotionality (Hersey, Blanchard, Johnson, 2007). Referring to the teacher leadership literature, it was found that the ways in which teacher leadership is key to present-day teaching effectiveness and a healthy future for student performance (Wilson, 1993). The literature further investigates the ways teachers assume leadership roles by exploring conditions that support or inhibit teacher leadership (Powles, 2016). Teachers are the schools' most valuable resource. Teachers, from neophytes to experts, fulfill formal and informal leadership roles within all schools. It is incumbent upon school leaders to tap this valuable resource as they initiate effective teaching-learning efforts and create sustainable practices that promote student achievement (Ysifro \& Salazar, 2010). Teacher leadership is defined as the ability to collaborate effectively with colleagues for the purposes of influencing change, increasing teacher expertise, and improving student and teacher learning.

With this basic assumption that teachers are leaders that make significant changes in students learning process, the study tried to explore what charismatic leadership characteristics presented among the Sri Lankan school teacher. The focused group interviews with twenty school teachers who are engaging in teaching to Grade 12 and 13 classes. The interviews were carried out at a private place (outside the school environment) where these teachers assembled for a teacher training program. The respondents included 15 female teachers and 05 male teachers, all of them are graduate teachers. After having them educated the objectives of the study the participants were closely taken to the dialog to better understand how they invest different characteristics in their teaching process. The responses were organized by key topics addressed by participants in response to interview questions aligned with the primary research questions. Studying the responses helped to determine, the themes, and insights of the respondents.

\section{RESULT AND DISCUSSION}

Looking closer at the teachers' personality, their psychological competence as part of their personal qualities plays a crucial role in working with students, their parents, or colleagues at school. Most of them are good psychologists, able to respond properly to different situations that require them to be more empathetic (Kelley, 2011). In order not to hurt anyone's feelings, or discriminate one student in favor of another, the teacher has to consider various situational aspects before his or her move or decision is made. At the same time, teachers usually have to give reasons for the measures they have taken in evaluating students. This happens, for instance, when they grade students' performance, when they comment on their students' knowledge level reached, or when they need to solve some problems or misunderstandings in the class (Bond, 2015). There are many different situations varying all the time, which require new solutions and measures or 'action logic' (Berry, Daughtrey, \& Wieder, 2010). This is also why the profession of a teacher as a leader is so demanding and difficult. 
According to the shreds of evidence collected, the teachers can play a highly significant but frequently underestimated role in improving student learning. Specifically, the available evidence about the nature of the effects of successful leadership on student learning justifies below important claims:

"Once, I found a student who was receiving poor grading in his tests during the last few years. He was an average student among others, but I realized that he has certain abilities which are not still uncovered and also not known by himself even. I noted that he was intelligent in numerous school activities. I myself closely talk to him and tend to carefully observe him. He was given performance targets and time to time looked at the achievements. Whenever necessary he consulted me. At those moments I sometimes acted taking unusual behaviors like going beyond the teacher role."

A 48 years old male school teacher who was having more than 15 years' experience with the young students describing experience says:

"During my full-service period, I was instrumental in moving more than 30 students better, who had different failures in their studies. My strategies included setting them goals, made self-sacrifices on behalf of them taking personal risk towards their progress, appeared confident about my proposals, incurred high effort to achieve the given targets, and made emotional appeals towards their progress. Sometimes the principles didn't rely on my expectation and they criticized the decisions I made for making such change in the students. It was a really surprising event to me once I understood that there were major transformations in students. Due to my guidance and directions, they progressed, making all of us wordless. I think it is a gift given by God to the teachers in the world."

One 53 years old teacher, who was acting as a deputy principal also in a rural area, expressed her involvement as below:

"I teach my student not during my official work hours only. I call my students to my home and spent with them about two hours per day doing exercises what has discussed in the classroom. Most of the poor students come to my place seeking extra attention. I do it happily and free of charge. The students are motivated to be excelled in what they have learned in the classroom revising several times. I am glad to say that I being a teacher, I was able to change the lives of most of the innocent students and gifted them to the country as worthy people." 
In-depth analyses of focused group discussions following charismatic characteristics were explored. Among the various dimensions of teacher leadership collected by means of individual interviews with teacher leaders, there are six main charismatic features were found in them. 1. Mission formulation for the students, 2. Unconditioned commitment towards the students' accomplishments, 3 . Trust on the students, 4. Taking personal-risk in directing students, 5. Demonstration of unusual behaviors and 6 . Emotional arousal through attractive communication were classified as these key characteristics.

In respect of mission formulation, the teachers whom we had discussions, often set a target to their students. They strategically show them future prospects for the students, sometimes with live examples. The way the teachers instill the future is impressive. Students perceive these are ambitious and thus work hard. If they find difficult to achieve these results, then the teachers put extra effort, even moving away from the teacher's role, but act as a parent. Mission formulation is especially important for students with low achievement motivation (Roles, 2015). While students with high achievement motivation performing well, they still expect the close supervision, fair appraisal, and recognition from the teachers. Teachers' guaranteed goals are able to enhance the performances of students with low achievement motivation. Therefore, these teachers put forward smart goals that encourage students to accomplish, when their motivation to achieve is low.

According to the discussion held with the teachers, it was realized that the teachers try to meet the students' needs by providing a variety of teaching methods, including direct instruction, grouping students, and rearranging the groups as needed. To reach the individual student, the teachers attempt to motivate each student by involving him or her in learning, and understanding how to teach everyone together while aiming to teach the average students paying individual attention. Some instances the teachers also be promoters for the students as individuals, ensuring their emotional courage need to succeed. They take steps to ensure that they don't marginalize or exclude any students because of their differences. They actively commit to the given teaching standards that allow them to best meet the needs of the students.

Sri Lankan teachers have trust on their students is proved by how they value the students learning experience, how they take examples from the students for teaching and how they use the language with the students in their teachinglearning process. Sometimes the teachers enlisted the students for making certain classroom decisions and give them increasing opportunities to make appropriate choices in relation to learning activities in the classroom. To increases, their sense of trust, control, and positive regard for active classroom participation are highly valued. It not only improves academic achievement, but also captures students' interest, and trust thereby preventing behavior problems that occur due to frustration, boredom, or dislike of learning. 
Teachers show personal risk-taking behaviors by way of caring the students as a responsibles elders, willingness to go above and beyond time spent in the classroom to help students, reaching the students who are disconnected from the school, and etc. They personally know their students. This can further help the teacher to find his or her passion. According to the most senior teacher having more than 40 years of teaching experience says, that she has chosen some behaviors which created her some unintended bad consequences, but she was brave to secure the higher performance of her students. Some teachers across the boarders to find the untapped strengths in students.

Unusual behaviors also are of vital in changing the students' frame of mind. Their risk-taking behaviors are unusual in Sri Lankan teachers. Their ability to inspire the students to learn is superior. These teachers use persuasive language that includes symbols, imagery, and comparisons that are relevant to the experience and values of the learning.

\section{CONCLUSION}

The Sri Lankan school teachers as leaders, set targets to the students when they are lack of clear understanding about their future study achievements. These teachers are all student-oriented at the school. They are speaking about students, their progress and wellbeing. They are transparent about the student's intentions. They also saw the support of students and their learning as the primary task. They have strong connections with students and able to positively influence and support the students as a role model. They often dedicate their personal time to provide students tutoring after school and on Saturdays. Most teachers believe that "teachers must get outside of the traditional teaching program. Their caring for students outside of the classroom is also commendable. These teachers believe that all students can learn. The guidance and the motivation towards their educational prospect are necessary for future success which could be given by the teachers. According to Hersey, Blanchard, Johnson (2007) the leader, need to be intellectual specialists of their fields.

Hence the discussions confirmed that the Sri Lankan Teachers are pretty much knowledgeable and excelled in communicational skills, tolerant and open for experience. It is also referred to Bryman's (1992) dimensions of charisma that are necessary to a charismatic leader. That is knowledge, skills, commitment to work or mission. According to the model of charismatic leadership, attractive leaders refuse regular condition, that means, they are not afraid of risk of challenging the status quo in order to reach the aim, try to endeavor to their goals by nontraditional methods, are persistent, self-confident, show attention to the needs of their subordinates, show example via role modeling. In the model of the transformational leadership created by Bass (1985), the charisma (honesty, reliability, intelligence, ability to communicate), and possession of a vision (ability to create appropriate persuasive guidelines for future) are indicated as being the most 
significant features. Leadership characteristics of the Sri Lankan school teachers are richer in these characteristics and are skillful communicators, possession of clear vision, ability to inspire the confidence of learners, ability to help the students to feel as capable, energetic and orientation to results, emotional expression and warmth and readiness to bear personal risks. In categorizing these characteristics into one class, Sri Lankan school teachers demonstrate charismatic leadership characteristics in their behaviors as teacher leaders.

\section{REFERENCES}

Bass, B.M. (1985) Leadership and performance beyond expectations. New York: Free Press.

Berry, B., Daughtrey, A., \& Wieder, A. (2010) Teacher leadership: Leading the way to effective teaching and learning. Center for Teaching Quality, (January), $1-12$.

Biviano, J. A. (2000) Charismatic leadership: An effective instrument for cultural $\begin{array}{llll}\text { Transformation (No. 6) } \quad \text { (Vol. } & \text { 58). Melbourne. }\end{array}$ https://doi.org/10.1017/CBO9781107415324.004.

Bond, Nathan. (2015). Teacher Leaders as Professional Developers. In Nadan Bond (Ed.), The Power of Teacher Leaders: Their Roles, Influence, and Impact (pp. 15-18). Kappa Delta Pi.

Conger, J. a., \& Kanungo, R. N. (1987). Toward a Behavioral Theory of Charismatic Leadership in Organizational Settings. The Academy of Management Review, 12(4), 637. https://doi.org/10.2307/258069

House, R., \& Aditya, R. (1997). The social scientific study of leadership: Quo Vadis? Journal of Management. https://doi.org/10.1016/S0149-2063 (97)90037-4

House, R. J. (1976). A 1976 Theory of Charismatic Leadership. in Howell, J. M., \& Shamir, B. (2005). The role of followers in the charismatic leadership process: Relationships and their consequences. The Academy of Management Review, 30(1), 96-112. https://doi.org/10.5465/AMR.2005.15281435 
Kanter, R.M. (1983). The change masters: Innovation and entrepreneurship in the American corporation. Simon \& Schuster: New York.

Kelley, J. D. (2011). Teacher's and Teacher Leaders' Perceptions of the Formal Role of Teacher Leadership. Dissertation, Georgia State University. http://scholarworks.gsu.edu/eps_diss/70

Leithwood, K., Louis, K. S., Anderson, S., \& Wahlstrom, K. (2004). How leadership influences student learning. The Wallace Foundation Center for Applied Research and Educational Improvement and Ontario Institute for Studies in Education New York NY, 2007(October 20), 1- 90. https://doi.org/10.1007/978-90-481-2660-6

Mansour Javidan and David A. Waldman. (2003). Exploring Charismatic Leadership in the Public Sector: Measurement and Consequences. Public Administration Review, 63(2), 229-242.

Ovando, M. N. (1996). Teacher leadership: Opportunities and challenges. Planning and Changing, 27, 30-44

Powles, J. M. (2016). Teacher Leaders' Utilization of Servant Leadership and the Impact on School Climate. Dissertation, Pro Quest LLC, http://media.proquest.com/media/pq/classic/doc/4318336621/fmt/ai/rep/NPD F? s=RbL1EN8OG 708TSFTqouRk9U\%2FAas\%3D

Sandberg, Y., \& Moreman, C. M. (2011). Common Threads among Different Forms of Charismatic Leadership. International Journal of Business and Social Science, 2(9), 235-241.

Shamir, B., House, R. J., \& Arthur, M. B. (1993). The Motivational Effects of Charismatic Leadership: A Self -Concept Based Theory. Organization Science, 4(4), 577-594.

Trice, H. M, \& Beyer, J.M. (1993). The cultures of work organizations. Englewood Cliffs, NJ: Prentice-Hall.

Waldman, D. A., Ramirez, G. G., House, R. J., \& Puranam, P. (2001). Does Leadership Matter? CEO leadership attributes under conditions of perceived environmental uncertainty. Academy of Management Journal, 44, 134-143 
Wilson, M. (1993). The search for teacher leaders. Educational Leadership, 50(6), 24-27.

York-Barr, J., \& Duke, K. (2004). What do we know about teacher leadership? Findings from two decades of scholarship. Review of Educational Research, 74(3), 255-316.

Ysifro C. Salazar, J. (2010). Teacher to Leaders: A mixed Methods Approach to Investigating Teacher Leadership in Program Improvement Secondary Schools. San Diago State University. 